\title{
Imagens da precariedade, governo dos pobres e implicações etnográficas ${ }^{1}$
}

\author{
Adriana dos Santos Fernandes \\ Pós-doutoranda pela Universidade do Estado do \\ Rio de Janeiro, Rio de Janeiro, Brasil \\ dricafernandes@yahoo.com.br
}

Resumo Através do trabalho de campo em ocupações de moradia situadas no centro do Rio de Janeiro, proponho pensar como a precariedade - imagens, sentidos, efeitos - é importante nessa experiência. O contexto político com a eleição de Lula da Silva para presidente foi algo que favoreceu a cena das ocupações. Poucos anos depoishouve uma retração: o anúncio de um projeto de gentrificação da área, o Porto Maravilha,que tornou-se aos poucos uma política de expulsão de camadas mais pobres da região. Para os moradores que acompanhei isso resultou na piora das condições materiais e das relações vivenciadas nos prédios ocupados. Abordo aqui como eles buscaram contornar essas políticas de gentrificação. Na última seção, a discussão recai sobre algumasdas implicações éticometodológicas suscitadas quando o campo da pesquisa é caracterizado por situações de precariedade.

Palavras-chave: Ocupações de moradia, pobres, precariedade, etnografia.

1 Este artigo reúne algumas ideias presentes na tese Escuta Ocupação: arte do contornamento, viração e precariedade, sob a orientação de Patricia Birman, no PPCIS/UERJ, defendida em 2013 e traz questões que desenvolvo no pós-doutorado pelo mesmo Programa. As primeiras versões desse texto foram apresentadas no Seminário (In)scrituras: sobre marcas e mapas corporais-espaciais, no PPGAS/MN/UFRJ, e no GT Periferias, da ANPOCS. Sou grata aos colegas do Seminário pelo diálogo e as parcerias que se seguiram, em especial a Adriana Vianna pelo convite e os comentários no GT. As reflexões que seguem são alegremente devedoras aos encontros promovidos pelo grupo Distúrbio (UERJ/UFRRJ), e à interlocuçãocom Patricia Birman. Agradeço também a(o) parecerista pela apreciação e sugestões. 


\section{Ponto de partida e proposição}

Desde o seu surgimento, a partir de 2004, as ocupações situadas na região central do Rio de Janeiro eram vistas pela maior parte de seus moradores como algo transitório e não definitivo. Ou, melhor, desde que se tornaram moradores de ocupações autogestionárias nesta área da cidade, a maioria dos ocupantes não julgava que isso encerraria os problemas relacionados à moradia (é certo que o longo histórico de despejos que os acompanhava pesou nessa avaliação). Já a militância envolvida na viabilização dos prédios encarava a experiência, de maneira geral, como uma alternativa capaz de assegurar habitação a camadas alijadas historicamente desse que éum direito constitucional. Para tanto, foram imóveis públicos abandonados os escolhidos para a empreitada. Iniciava-se o primeiro mandato presidencial de Luís Inácio da Silva, o Lula, e uma de suas promessas de campanha era que em seu governo prédios públicos em desuso seriam transformados em moradia popular.

E foi desse contexto político favorável que despontaram, entre 2004 e 2008, cinco ocupações autogestionárias da área central do Rio de Janeiro: Chiquinha Gonzaga, em 2004 (em 2013, através do dispositivo constitucional concessão para uso especial, seus moradores tiveram assegurados o uso do imóvel por um período de 99 anos); Zumbi dos Palmares, em 2005 (esvaziada no final de 2011); Flor do Asfalto, conhecida como a ocupação dos punks, em 2006 (despejada no final de 2011); Quilombo das Guerreiras, em 2006 (despejada em 2014); e Machado de Assis, em 2008 (esvaziada em 2012); todas localizadas na zona portuária, embora a primeira ocupação se encontre a três quarteirões da principal avenida do centro, a Presidente Vargas. ${ }^{2}$

Vale lembrar que nas ruas contíguas e transversais à R. Barão de São Felix, onde estásituada a Chiquinha Gonzaga, desde o final do século XIX, sempre pulularam invasões, cortiços, hospedarias a preços módicos (ainda que custosas para a população que as habita). Além disso, na região funcionam um restaurante e um Hotel (mencionado por ocupantes como o restaurante do Garotinho ou do Betinho; e o Hotel [hotel da Central ou hotel popular]) ${ }^{3}$, onde as refeições e os quartos custam 1 real (os dois são mantidos e administrados pelo governo do Estado). Para a população pobre esta éuma região pulsante e importante da cidade. Camelôs, prostitutas, moradores de áreas metropolitanas, trabalhadores de trens, metrôs e ônibus que transitam por estas regiões, mendigos, população de rua, usuários de droga, ambulantes os mais variados, entre outros tipos, circulam por ali diariamente, compartilhando o mesmo espaço.

2 A Frente de Luta Popular existiu entre 2000 e 2009, tornando-se conhecida graças às ocupações autogestionárias organizadas pelo grupo no centro do Rio. A Frente era composta por universitários e por militantes egressos de outros movimentos, como o coletivo Gregório Bezerra (ligado originariamente ao PCB). Outros ainda tinham participado de grupos anarquistas, feministas, afro e do movimento estudantil.

3 Palavras grafadas em itálico referem-se a expressões registradas em meu caderno de campo ou a noções devidamente creditadas a seus autores. 
Por sua vez, a notícia de que um prédio de dez andares havia sido ocupado bem próximo à Estação Central do Brasil, no coração do Centro antigo da cidade do Rio de Janeiro, repercutiu na região. Moradores e militantes contaram que tal notícia, na época, provocou um verdadeiro efeito enxame. ${ }^{4}$ As pessoas passavam na Chiquinha Gonzaga perguntando se havia vaga no prédio e, diante da resposta negativa, indagavam se eles não iriam realizar uma nova invasão pelos arredores. A informação que essa ocupação não possuía um grupo dirigente, ou que ninguém precisava pagar qualquer tipo de taxa, ou, ainda, que não havia um "dono" da mesma, contribuiu positivamente na produção desse efeito enxame.

A possibilidade de morar no Centro sem pagar taxas era algo destacado com frequência pelos ocupantes que, em geral, tinham de se deslocar de regiões distantes da cidade (onde são péssimas as condições de transporte) para trabalhar na região central ou adjacências. Neste caso, desembolsando de seus ganhos para custear um quarto ou dividir algum espaço nas hospedarias ou cortiços da área. Ou ainda, tendo que passar alguns dias dormindo na rua e pagar pelo uso de banheiros e depósitos para conseguirem guardar seu material de trabalho (carroças, bancas e/ou mercadorias [a maioria trabalhava como ambulantes/ camelôs] e burro sem rabo [se ganhavam a vida como catadores]).

A diferença de perspectiva entre invasores e militância quanto ao sentido das ocupações, ao se encontrar com os ventos pouco auspiciosos que tomaram o local (para os pobres e outros indesejáveis da região), terminou por engrossar as forças que desejavam o desmantelamento dos prédios autogestionários. Os tais ventos chegaram após os anúncios de que a cidade e o país receberiam a Copa do Mundo de 2014 e os Jogos Olímpicos de 2016, respectivamente. Assim, tal encontro, ou melhor, a "trombada" do projeto de moradia popular (as ocupações autogestionárias) com os megaeventos acima terminou por estreitar o horizonte dos ocupantes. Minando os planos da militância de transformação das ocupações em algo que, além de servir como moradia, agregasse novos (micro) movimentos (embora isso tenha ocorrido, em certo grau), e que, da mesma forma, propiciasse debates e encontros mais diversos. ${ }^{5}$

A chegada desses ventos pouco auspiciosos se materializou na cena das ocupações, através de um imaginário que assinalamos como paranoide. Os boatos de que o empresário Eike Baptista compraria o prédio da ocupação Zumbi dos Palmares e que a apresentadora Xuxa Meneghel estaria por trás das pressões que desejavam o esvaziamento da Machado de Assis, ou de que o primeiro seria anexado ao edificio vizinho que jápassava por uma ampla reforma, de modo que surgisse um grande shopping center, ou, ainda, que o mesmo imóvel viria abaixo depois de ser implodido; mais as intervenções drásticas na avenida que passava em frente ao imóvel (a via manteve-se interditada à passagem de automóveis por

4 Efeito enxame faz alusão às seguintes observações e autores: “[...] Enxamear parece indicar que um gesto pequeno e local, um gesto dos pequenos, pode adquirir uma enorme força" (Caiafa, on-line); "Um enxame de gafanhotos trazido pelo vento às cinco horas da tarde [...]" (Deleuze; Guattari, 1997, p. 49).

5 Como exemplo, uma pauta de sugestões foi tirada visando a redefinição do Plano Diretor da cidade (tais encontros aconteceram na ocupação Chiquinha Gonzaga, entre 2005 e 2007). 
quase dois anos, tendo seu asfalto retirado e um canteiro de obras acontecendo a passos de tartaruga), engordaram sobremaneira este imaginário paranoide. ${ }^{6}$

Igualmente, a entrada de uma Unidade de Polícia Pacificadora (UPP) no morro da Providência, valorizando os imóveis e terrenos situados na região, o que, na sequência, contribuiu para promover a entrada do tráfico nos prédios das ocupações; também os rumores de que uma parte da calçada da rua Barão de São Felix seria retirada para a abertura de uma ampla via para veículos (e que poderia significar a derrubada do prédio da ocupação Chiquinha Gonzaga, desde sempre a principal referência nessa cena). Tudo isso, por sua vez, entre várias outras narrativas de cunho persecutório, sugeriam quais os tipos de dispositivos estatais e governamentais estavam sendo convocados.

Esse imaginário paranoidese orientava, sobretudo, por disse e me disse, ou, disse e desdisse, por rumores, fofocas, informações desencontradas, agentes governamentais que apareciam para desaparecer, além de um verdadeiro labirinto de informações sobre quais os procedimentos e práticas judiciais deveriam ser tomados. Isso tudo gerou uma atmosfera bastante tensa entre ocupantes, militantes, estudantes e apoios articulados em diferentes esferas (movimentos sociais locais, Defensoria do Estado, Instituto de Terras [ITERJ] e ONG).Aos poucos solapando que este conjunto de personagens continuasse se estabelecendo como um contraponto efetivo ao processo de gentrificação que ganhava cada vez mais fôlego e pernas. Ao mesmo tempo, todo esse repertório ressoou como um alerta sobre os limites presentes nesse horizonte e atéque ponto a ocupação conseguiria avançar.

Em 2009 a região portuária (que passou a englobar também algumas áreas do centro antigo) foi objeto de um projeto por parte da prefeitura nomeado de Porto Maravilha. Em seguida, com o apoio do governo federal, e de recursos cedidos através da Caixa Econômica Federal, um consórcio público-privado foi inaugurado com vistas a conduzir os investimentos na região.

Desde então alguns conflitos que jáexistiam nos prédios da Machado de Assis e Zumbi dos Palmares se intensificaram (o vetor tráfico [de drogas] tornou-se ainda mais atuante nesses espaços). Foi nesta ocasião que a pergunta sobre a continuidade das ocupações se colocou de forma premente entre moradores, militantes e pesquisadores. E a aposta da viabilidade da ocupação como um espaço autônomo (sem um "dono", um movimento ou partido que a dirigisse) e de convivência (o que incluía a capacidade de moderar conflitos) foi se esvaindo. A quantidade de queixas referentes à sujeira que invadia o prédio da Zumbi dos Palmares e o clima caótico que instalou-se na Machado de Assis,

6 A ideia de um imaginário paranoide refere-se às observações de Gilles Deleuze a respeito do que é designado pela psiquiatria como delírio monomaníaco, passional ou de reinvindicação (e que se diferencia do delírio interpretativo, em que cada signo remeteria a outro signo, e este conjunto de signos a um significante central). Esse imaginário paranoide, ou esse delírio passional, ou, ainda, delírio subjetivo, seria constituído por pontos de subjetivação ou ocasiões exteriores ("que pode ser qualquer coisa, pequeno pacote de signos localizados, [...], piscar de olho, [...], lingerie,sapato, rosto que se desvia"), capaz de "mergulhar em uma linha reta" para se "segmentarizar em processos sucessivos, com intervalos variáveis". Por fim, esse mesmo imaginário "seria do plano da ação, mais do que da ideia" (Deleuze; Parnet, 1998, p. 126-127). 
assim como as diversas modalidades de boicote às tentativas de organização do prédio da Zumbi, absorviam e extenuavam o cotidiano. Somaram-se a isso, os desmandos de um ou outro que se dizia do tráfico ou de grupos realmente associados a este, as ameaças de vários tipos e de ordens diversas, as brigas e implicâncias entre vizinhos ou entre parentes distantes ou próximos, acirradas nesta época, transformando o cotidiano das ocupações num verdadeiro inferno - conforme repetiu uma moradora.

Desse modo, a ideia de que as ocupações poderiam se constituir como coletivos horizontalizados, funcionando de modo não representativo, foi aos poucos soterrada, talvez possamos dizer, na mesma medida em que os tratores do Consórcio Porto Novo formado pelas empresas Odebrecht, OAS e Carioca - revolviam as ruas da região.

Seguindo a pista de Vera Telles de que devemos levar a sério as novas configurações do trabalho e que, para entendê-las no interior das cidades, é preciso acompanhar não apenas as relações ou vetores horizontalizados entre trabalho, cidade e espaço, mas "os agenciamentos sociais em torno dos quais desigualdades, controles e dominações se processam" (Telles, 2010, p. 115), nossa aposta é de que alguns desses agenciamentos relacionados à ideia de precariedade e manejados no contexto das ocupações referidas nos ajudam a entender como os mecanismos de governança dos pobres (e de reatualização da desigualdade) têm operado numa metrópole como a do Rio de Janeiro. Da mesma forma que os pobres não configuram esse plano como simples objetos dessas políticas, mas constituem, tencionam e se apropriam, em graus e escalas variadas, dessa composição.

Propomos, para tanto, apresentar algumas passagens de campo em momentos diferentes (das ocupações) que nos ajudam a pensar como a precariedade (incluso o viver em condições de precarização) e as imagens que podemos associar a este termo sofreram gradações e uso dissonantes. Ao mesmo tempo em que são importantes para compreender como as práticas do estado e os agentes da prefeitura ganharam outra feição quando o processo de gentrificação da região se intensificou. ${ }^{7}$

\section{Positivar a precariedade}

Nossa perspectiva segue as observações de Giorgio Agamben (2004) de que o paradigma dominante da política contemporânea é o campo, e com Michel Agier, que favelas e ocupações, entre outros, seriam modalidades de campo,${ }^{8}$ onde diferentes regimes

7 Sobre esse processo ver:Birman; Fernandes; Pierobon (2014).

8 “[...] olhar o campo não como um fato histórico e uma anomalia pertencente ao passado (mesmo que, eventualmente, ainda verificável), mas, de algum modo, como a matriz oculta, o nómos do espaço político em que ainda vivemos” (Agier, 2009, p. 173). 
de indeterminação ou de exceção ${ }^{9}$ operam, resultando na sobreposição e na recorrência de modalidades de violência/usurpação em seus espaços. Segundo Agier: onde a "vida cotidiana é, por conseguinte, marcada por [...] uma violência interna que duplica a violência de guerra ou social [...]"(2009, p. 126).

Serápreciso entender, consequentemente, tanto essa dinâmica quanto problematizar os efeitos que essa experiência provoca em termos de narrativa. Da mesma forma, para notar a heterogeneidade que atravessa essa modalidade campo e assinalar que esses espaços nem estão inscritos no vazio, nem as pessoas envolvidas são personagens passivos e opacos, incapazes de se apropriar, em alguma medida, de sua existência, de compor mundo ou de produzir modos de resistência (Foucault, 1985, p. 82). Esses modos são engendrados, por sua vez, a partir de arranjos, vínculos e agenciamentos cotidianos envolvendo os mais diferentes agentes e instituições estatais e nãoestatais (filantrópicos, movimentos, familiares, etc) ${ }^{10}$.

E se retomamos a máxima de Walter Benjamin de que os vencedores continuam vencendo e silenciando os vencidos (Benjamin, 2005), principalmente através da narrativa que engendram, nossa aposta éperscrutar quais os ecos presentes nessa mesma narrativa capazes de atemorizar sua "paz". Ou seja, o que não entra nessa "grande" narrativa que pode ser rememorado de maneira a produzir outras narrativas mais fragmentárias (e fragmentárias no sentido de que se propõem a incluir perspectivas minoritárias ou que foram silenciadas). Ora, para pensar alternativas de constituição de resistências "fora do Estado" (Butler, 2014), do corpo em si enquanto corpo político em afirmação, em seus vestígios e inscrições pela cidade, por exemplo, e pensar essas resistências nos modos de

9 O termo exceção ou estado de exceção utilizado por Agamben advém da noção homônima e célebre de Walter Benjamin que diz: “A tradição dos oprimidos nos ensina que o 'estado de exceção' no qual vivemos é a regra. Precisamos chegar a um conceito de história que dê conta disso. Então surgirá, diante de nós, nossa tarefa, a de instaurar o real estado de exceção; e, graças a isso, nossa posição na luta contra o fascismo tornar-se-á melhor" (2005, p. 87). O conceito ampliou-se graças à obra Homo Sacer (2004), do filósofo italiano Giorgio Agamben. Para ele, a exceção ou estado de exceção, está presente nas situações em que a fronteira entre a lei e a não lei são incertas, compondo o que chamou de zonas de indeterminação, nas quais as figuras do homo sacer, de uma vida matável, uma vida indigna de ser vivida podem despontar (Agamben, 2004, p. 182).

10 Sobre a ideia de um circuito dos pobres ou da população em situação de rua por equipamentos estatais, filantrópicos, movimentos sociais e do Terceiro Setor remeto aos trabalhos presentes no volume organizado por Rui, Martinez e Feltran (2016), ao trabalho de Mariana Martinez (2014) com ênfase no papel da saúde, Daniel De Lucca e a circulação da população em situação de rua na cidade de São Paulo, a etnografia de Taniele Rui sobre os usos de drogas e a relação com os espaços públicos (2013), ao dossiê organizado porVera Telles (2017) para a revista Ponto Urbe, com os trabalhos de Deborah Fromm, Tais Magalhães e Fabio Mallart/Taniele Rui. João Biehl (2016) tem se dedicado a cartografar os mercados terapêuticos e a judicialização da saúde, e os artigos reunidos em Affliction, de Veena Das (2015) são igualmente demonstrativos do quanto é complexa a trama envolvendo pobreza, saúde, assistência social, mercados e violência em regiões periféricas. 
subjetividade, o que significa perseguir a produção de um outro social, ou, noutros termos, perseguir modos minoritários de existência. ${ }^{11}$

Nossa proposição é a de privilegiar a precariedade não como falta ou como algo negativo, mas como uma apropriação, em diferentes planos e escalas, pelos interlocutores do terreno (moradores das ocupações mencionadas). A precariedade não atuaria apenas no registro da vitimização, da submissão ou da cordialidade, de forma a revalidar formas de dominação/disciplinarização. Mas consiste numa estratégia para contornar os mecanismos de usurpação e violência que atravessam essa cena. Para tanto, seguimos as pistas de Judith Butler (2010) quando esta diferencia o viver em condições de precarização (precarity) da noção de precariedade (precariouness) ou do viver precário (precarious life).

A primeira, a precarity, ou o viver em condições de precarização, designa "uma condição politicamente induzida, em que certas populações adoecem por falta de redes de apoios sociais e econômicos e estão diferencialmente mais expostas aos danos, à violência e à morte, se encontrando em grave perigo de doenças, pobreza, fome, deslocamento e de exposição àviolência sem nenhuma proteção" (Butler, 2010, p. 46).

A segunda noção, precariouness ou viver precário, diz respeito a uma condição de interdependência "[...] no reconhecimento da vidacomo algo que só se sustenta a partir de múltiplas contribuições” (Ferreira, 2015, p. 103). Nas palavras de Butler: "Tanto a precariedade, quanto a precarização são conceitos que se interceptam. As vidas são, por definição, precárias: podem ser eliminadas de maneira voluntária ou acidental, e sua persistência não estágarantida de nenhum modo. Em certo sentido, éum traço de toda a vida, e não existe uma concepção de que a vida não seja precária, salvo, todavia, na fantasia, e particularmente nas fantasias militares" (2010, p. 46).

Para dar consistência ao que estou propondo, entraremos finalmente na seara etnográfica. Quatro cenas serão apresentadas como uma tentativa de distinguir três tempos concernentes às ocupações da área central do Rio de Janeiro (esses três tempos ou modos de existência surgem aqui na medida em que acredito que nos ajudam a pensar as singularidades constituintes deste tipo de moradia). Embora a narrativa desses momentos esteja baseada num recorte cronológico "conservador", ou seja, compreendido na sequência passado-presente-futuro, a ideia é enfatizar os atravessamentos e sobreposições inscritos nesse plano.

Os três tempos que escolhi são uma forma de especificar três aspectos da relação entre pobres e/ ou "indesejáveis" e agentes do estado/ políticas para a região portuária/ Centro:

11 Segundo Deleuze: "Minoria designa primeiro, um estado de fato, isto é, a situação de um grupo que, seja qual for o seu número, está excluído da maioria, ou está incluído, mas como uma fração subordinada em relação a um padrão de medida que estabelece e fixa a maioria. Pode-se dizer, neste sentido, que as mulheres, as crianças [...] são ainda minorias, por mais numerosos que sejam. [...]. Mas há, imediatamente, um segundo sentido: [...] cada um constrói sua variação em torno da unidade de medida despótica e escapa, de um modo ou de outro, do sistema de poder que fazia dele uma parte da maioria" (2010, p. 63-64). 
- $1^{\circ}$ tempo: trago duas cenas que demonstram o quanto os ventos (se não podemos dizer favoráveis) não se mostraram impeditivos àpermanência de ocupações e de seus "indesejáveis";

- $2^{\circ}$ tempo: as ameaças de esvaziamento e retirada da população pobre começava a acontecer e a possibilidade, sob o ângulo dos ocupantes, de barganhar algo razoável em troca, encontrava-se envolto em nuvens;

- $3^{\circ}$ tempo:pode ser apreendido como um momento de intensificação do quadro de usurpação/ violência, presente anteriormente. Mesmo com a garantia de moradia via judiciário, duas moradoras, depois que veem a ocupação invadida pelo tráfico (que toca o terror no local), e dos efeitos diretos e indiretos da gentrificação em suas vidas (para pior), estão absolutamente obsessivas para se mudarem da ocupação para apartamentos do Minha casa, minha vida construídos num bairro vizinho.

\section{Precariedade e viração $\left(1^{\circ}\right.$ tempo/cena 1$)$}

Em 2008/2009, Giane, que circula pelo centro com dois filhos, uma menina de cinco anos, e um bebêde alguns meses, anda sempre descalça. Chegou na ocupação (Machado de Assis, zona portuária) porque um militante e morador de outra ocupação a avisou sobre a nova invasão. Os militantes e moradores "pioneiros"12 não queriam aceitá-la imediatamente como moradora (o prédio era bem maior do que se imaginou, e muitos ocupantes que invadiram o edificio meteram o pé na primeira semana). Chamava minha atenção (e de outros ocupantes) o fato de Giane, a despeito de sair pela manhã vestindo um par de chinelos ou outros calçados que ganhara no dia anterior, retornar ao prédio invariavelmente descalça. (Ela também recebia doações de roupas que também desapareciam sem deixar vestígio). Para conseguir ser aceita no imóvel, nossa heroína não esmoreceu: chegou ao final da manhã e permaneceu um dia inteiro prostrada diante da Machado de Assis. O militante responsável por trazê-la estava dentro do lugar argumentando a favor de sua entrada pelo viés da urgência: deveriam abrir uma exceção porque ela realmente necessitava de um lugar. Giane, por sua vez, não se mostrava abalada ou aborrecida com a longa espera e estava mesmo - posso talvez dizer - plácida com a situação. Aumentando, inclusive, o incômodo (meu e de outros participantes), ao resolver esperar a decisão do coletivo sentada exatamente rente (bastante rente, aliás) a um filete com uma água fétida que escorria do pátio do prédio para o buraco do esgoto da rua.

Depois de longas horas, após a assembleia da noite, quando a entrada de Giane não fora consentida pelo grupo operativo [que organizou a ocupação], o militante e morador que havia a chamado para a Machado de Assis decidiu abrir o portão contrariando a decisão do operativo. A entrada de Giane, por sua vez, foi recebida sob urros e aplausos dos moradores comuns [termo meu].

Outro artefato/acoplamento fundamental na composição dessa interlocutora era um carrinho de bebê que portava em situações fora da ocupação.

12 Grupo que participou das reuniões para a viabilização e organização da ocupação por cerca de dez meses antes da entrada no imóvel. 
Interessante observar que nem sempre o veículo servia para transportar seu bebê (ela possuía uma bebezinha de nove meses). Este mesmo carrinho trazia uma grande bolsa de napa, além de outros apetrechos: sacolas plásticas com produtos de mercado, sapatos, panos - inclusive a sandália da vez: aquela com a qual saía pela manhã e que desparecia no decorrer do dia.

Se nossa infame (numa apropriação do termo usado por Michel Foucault em $A$ vida dos homens infames) era vista como doida, maluca, não bate bem, tem um parafuso a menos [expressões nativas], também pode ser reconhecida em uma qualidade fundamental a quem está em condição de precariedade: circulava com grande desenvoltura para realizar transas $^{13}$ as mais diversas. ${ }^{14}$ Nas pistas exploradas por Epele, a aposta é pensarmos a pobreza não como escassez, mas como uma positivação dos modos de circular, negociar, cuidar e constituir redes que perpassam e embaralham os planos mais diversos: morais, afetivos, econômicos; e também os sentidos do viver e do morrer - que assinalamos como uma modalidade fundamental à viração.

As transas de Giane eram inúmeras: possuía um verdadeiro mapa dos pontos de entrega de comida no centro da cidade (a melhor e a pior quentinha, idem para o caféda manhã); cultivava sua relação com uma madrinha da Baixada Fluminense através de visitas semanais ou quinzenais; também o contato com uma assistente social do centro; o contato com os meninos (trabalhadores do tráfico de drogas) do morro da Mangueira (que a deixaram, quando aconteceu o esvaziamento da ocupação, habitar um imóvel no alto do morro sem que precisasse pagar nenhuma taxa). Sem contar os namoros: durante os inúmeros encontros pelo Centro, durante a pesquisa de doutorado, mencionava sempre alguma estória relacionada a seus namorados, a facilidade com que percorria a rede da militância - no caso dela, por andar constantemente preocupada, entre outras coisas, em arrumar uma outra ocupação para cair, quando finalmente a prefeitura cumprisse o enunciado de que a Machado de Assis seria lacrada.

Assim, neste existir pela viração, empurrar um carrinho de bebê pela cidade lhe abria portas, assegurava a sua subsistência, ativava e ampliava a sua rede de contatos. Andar maltrapilha e descalça (e todos os efeitos que isso gerava) operava como um "ganho

13 Com transas/transar retomo a desconstrução e a polissemia do termo proposta por Maria Epele, em Sujetar por la herida (2010), a respeito da drogadição entre pobres em Buenos Aires.

14 Embora os contextos sejam diferentes, a ideia de uma (certa) economia de trocas/intercâmbios (el transar) me parece muito oportuna para nos ajudar a compreender a cena das ocupações. Segundo Epele: "Ao integrar a incerteza, essa economia de trocas se converte em uma prática e uma teoria sobre as armadilhas e as capturas das desordens sistemáticas presentes em contratos e acordos, e nos modos em que as desigualdades comprometem e resultam em dependências e sujeições, e de como produzem divisões, fraturas, conflitos e violência. [...] esta economia dos intercâmbios implica a mobilidade e transitividade entre múltiplas posições, desde capturar outros e ser capturado por outros [...]. Nesta mesma dinâmica, o mostrar-se capturado e vulnerável nas transações é ficar exposto à vergonha pública, ao bardeo [“navalha”], a humilhação. Esta posição compele, em alguns casos, a levar a cabo ações para restituir a dignidade, e que buscam desmentir o fato de serem reconhecidos como vítimas" (2010, p.93). 
secundário", ao mesmo tempo em que reatualizava a imagem de "pobre coitada" que, inevitavelmente, precisava estar inserida nos circuitos da assistência social, da filantropia e do movimento de sem-teto da região da Central. Entretanto, em contrapartida, esse mesmo deslocamento era decisivo para assegurar sua "autonomia"/deslocamento pela cidade, e, igualmente, para que ela não se tornasse um zumbi. ${ }^{15}$

\section{Precariedade, circulação e redes $\left(1^{\circ}\right.$ tempo - cena 2$)$}

Uma segunda positivação da precariedade pode ser pensada no juízo corrente de que nenhum morador vê a ocupação como algo definitivo. ${ }^{16} \mathrm{~A}$ passagem a seguir demonstra um dos sentidos fortes que a ocupação/invasão possuía, segundo a visão de um morador de ocupação e também militante, por exemplo, entre moradores oriundos da rua:

Eu até acho que as pessoas [...] venham para a ocupação para isto mesmo, mas [só] depois que as pessoas se instalavam e permaneciam um tempo. [...] Vi pessoas que moravam parte do tempo na rua e parte do tempo numa pousada, tipo: eu fico um ou dois dias numa pousada, fico um tempo na hospedaria, dois, três dias na semana, aí então eu tomo banho, me ajeito um pouco, dois ou três dias eu durmo na rua. Talvez o dinheiro do cara que é camelô, que tem muita situação que você mora na Baixada Fluminense, ou morava na zona oeste $[\ldots]$ você vem para o centro, $[\ldots]$ pra vender alguma coisa, pra depois ter algum dinheiro, e não dá pra voltar todo dia porque senão o dinheiro seria quase todo pra pagar a passagem. Aí o cara começa a passar dois, três dias aqui [na ocupação] (acho que é até melhor ele ficar logo aqui, não tem família, ou quer as pessoas da família venham também). Talvez as pessoas optem por esse negócio: de passar alguns dias na hospedaria e outros dias na rua, porque se eu fico na hospedaria hoje, tomei banho, me arrumei, se passar uma noite na rua, não sei se vocês notam, não dá muito problema. Mas se começar a passar todo dia, um dia, dois, sem tomar banho, lá pelo terceiro ou quarto dia... Tinham várias pessoas que viviam assim, inclusive o José, o cara nem parece que morou na rua. $\mathrm{O}$ cara andava todo arrumadinho. Eu tô aqui [na ocupação] pra arrumar meu arroz, meu feijão, e pronto. E quando vem a ocupação, você tinha um carrinho pra vender na rua, mas aí você tinha que guardar num lugar que tem que pagar, senão os outros pegam. Porque é provável que vai aumentar [o preço para guardar um carrinho em algum lugar no centro]. Com o Choque de Ordem, eles tomaram até galpão inteiro. Então o que acontece: maior procura, gera um

15 Vários dos ocupantes antes de chegarem à ocupação encontravam-se na rua e, como alguns relataram, eram um zumbi, se imaginamos uma escala da precariedade, era encontrar-se não apenas na pior posição quanto às condições materiais de existência mas, principalmente, era descobrir-se numa posição mais suscetível à "morte matada" e a outras violências que o estar na rua encerra (tendo como referência cidades brasileiras de médio e grande porte).

16 A sentença dos agentes do judiciário ecoa essa análise quando enuncia que é responsabilidade da prefeitura "[...] tomar as medidas cabíveis para que o imóvel não venha a ser invadido em seguida após o seu esvaziamento”. In:Tribunal da Justiça Federal. $2^{a}$ Região da Seção Judiciária do Rio de Janeiro. Processo n ${ }^{\circ}$ 2005.51.01.007798-0. 
aumento do preço. Ninguém quer pegar uma bolsa só para guardar. Guarda pra você só quem gosta de você, confia em você. [...] Enfim, quando chega a questão da ocupação o cara vêa probabilidade dele melhorar a situação. ${ }^{17}$

Este melhorar a situação, contudo, não apagava o longo histórico de despejos (ocasionados por diferentes motivos) que marcaram/marcam a trajetória de parte significativa das pessoas que participavam da empreitada, muito menos desfez a avaliação de que era diminuta a chance delas permanecerem. Repisando a opinião quase que hegemônica dos moradores de que não almejavam permanecer o resto da vida numa ocupação, como explicitou um jovem ocupante, quando seu prédio havia sido tomado por traficantes e os garotos do movimento instalaram uma estica e começaram a tocar o terror entre os moradores.

Nessa perspectiva, a ocupação deveria servir, se a imaginamos como um caso de "sucesso", para conseguir um lugar melhor do que aquele em que estavam quando resolveram seguir os ventos “estão invadindo por lá” (Alves; Telles, 2006, p. 327). Portanto, é no plano de viração que a ocupação se insere (ou pelo menos esse tipo de ocupação autogestionária), mas é uma viração que enseja melhorar as condições de moradia de seus habitantes, nestes exemplos, em médio prazo. E foi principalmente quando um horizonte tomado por ameaças e ações de desmantelamento das ocupações embaçou a paisagem (com a gentrificação da zona portuária), que seus moradores se esmeraram mais ainda por discriminar e avaliar as melhores e piores oportunidades (termo repetido muitas vezes pelos ocupantes, em diferentes situações).

Encontrei Giane por acaso no centro e ela conta animadamente que um agente da prefeitura chegou à ocupação oferecendo cinco mil reais, caso os moradores saíssem o mais rápido do imóvel. Indago-lhe se ela não pensava em comprar algo para morar. Para a minha surpresa ela me responde com um lacônico não, e emenda a conversa me perguntando se eu sabia sobre a nova ocupação que estava para acontecer. Ou se havia vaga nas ocupações que eu conhecia, se na Flor do Asfalto dava para ficar - mas ela mesma replicou dizendo que havia encontrado um militante e morador da mesma Flor do Asfalto que contou que esta seria esvaziada em breve.

Num outro encontro, também por acaso, Giane reclama sobre a Machado de Assis, ressoando alguns motes - que ela andava infernal, caótica, um muquifo, uma favela - sobre as condições dessa ocupação, após dois anos de seu início. Afinal, três invasões e seus invasores haviam se mudado num curto período para a Machado de Assis, o que gerou um clima de muitas brigas e tensões diárias. Fato é que o tráfico instalara uma pequena boca no local. Além disso, como moradores e militantes contaram, negociava frações do terreno batizado de Nárnia, também pertencente à ocupação. Então quando Giane me respondeu sobre como andava a Machado de Assis, Ah a ocupação tá daquele jeito mesmo que você conhece. Não mudou nada não e ela está para sair. E eu,

17 Entrevista realizada em outubro de 2012 com um morador e militante da Chiquinha Gonzaga e importante interlocutor de campo. 
capturada em sua primeira sentença e mouca para a segunda, tentei completar: É, muita gente anda dizendo que não está legal, que o tráfico está mandando, que uma cabeçada de gente se mudou para lá... E ela: Ah, não, na verdade, é que eu e meu marido estamos brigando demais...

Já a última assertiva eu escutei bem e serviu para realocar as duas frases num contínuo: A ocupação está daquele jeito que você conhece, não mudou nada [...] ]e Eu e meu marido estamos brigando demais. Assim, as duas cenas com Giane se conjugam para mostrar a perspectiva da precariedade como um elemento primordial que lhe confere alguma autonomia pelo Centro da cidade: seja pelas redes e os modos de circulação urdidos, seja pelas várias negociações, transas/trocas que acompanham esse quadro. Circulação e nomadismo que lembram a máxima de Walter Benjamin:“[...] onde outros encontram muros e montanhas, ela vê caminhos por toda a parte”(1979, p. 302). E este é o mote para adentrarmos ao segundo momento, o momento onde as tensões se inscreveram de maneira contundente.

\section{Precariedade e destruição (2 $2^{\circ}$ tempo - cena 3$)$}

Militantes de uma ocupação da zona portuária querem que os moradores, depois de um ano ocupando o imóvel, deem seus dados para a realização de um cadastro por apartamento. Assim, poderiam entrar na Defensoria Pública pedindo a concessão de uso sobre o imóvel (cada apartamento/ quarto ficaria associado a um nome). O que significava que os apartamentos não poderiam ser negociados ou vendidos. Os moradores não concordam em fazer o cadastro. Segundo a análise de um militante a respeito, isso, na verdade, seria jáum sinal sobre as dificuldades que a Zumbi dos Palmares iria enfrentar [essa fala aconteceu quando a gentrificação ${ }^{18}$ havia se instalado e os rumores de que os moradores queriam negociar o prédio com a prefeitura repercutiam amplamente].

O militante se referia a inabilidade dos moradores quanto a manterem a ocupação e as inúmeras brigas e o grau de violência presentes nessa disputa. Um mês antes de esvaziarem a ocupação corre a notícia de que um homem fora assassinado dentro do prédio. O rapaz era tido como drogadito e por conta do vício havia roubado um fogão de outra moradora. Alguém viu, alguém dedurou. Quando ele voltava para a ocupação começaram a porrá-lo. Sua irmãtenta interceder. A briga se intensifica e o morador drogadito, por fim, éarremessado pela janela e cai na marquise do prédio. O marido da irmãdeste éaçougueiro e ao chegar à ocupação parte para cima de alguns moradores. Fere quatro, e é colocado para fora. Marcas de sangue permanecem nos andares durante a semana. Outros moradores invadem o apartamento do açougueiro, retiram as carnes que ele guardava no refrigerador, espalhando-as pelo chão do apartamento. Estas permanecem dias no mesmo local, até apodrecerem [conforme narraram moradores semanas após o ocorrido].

Moradores ligam para a polícia contando sobre a morte do rapaz. O

18 Uso o termo gentrificação de maneira pontual, para referir às políticas urbanas anunciadas em 2008 e 2009 e tocadas nos anos seguintes, e, em especial, às políticas ligadas ao projeto Porto Maravilha, justificadas por preparar a cidade para a Olimpíada, de 2012 e a Copa do Mundo, de 2014. 
atendente da polícia responde, entretanto, que a polícia não poderáaparecer na ocupação porque estavam todos na operação do Complexo do Alemão (era novembro de 2010). Por fim, conseguem uma ambulância da SAMU (Serviço de atendimento móvel de urgência) para pegarem o corpo.

Um cartaz afixado por Lídia [de orientação pentecostal e líder entre os moradores da chamada transição da ocupação para as mãos da prefeitura] na entrada do prédio contém os seguintes dizeres: Por favor, não falte porque já deu certo $^{19}$.

Walter Benjamin em seu texto O caráter destrutivo (1979 [1931]) distingue dois tipos de mulher e homem. Haveria um tipo estojo e outro, de caráter destrutivo ${ }^{20}$. Esses estilos que o filósofo das Passagens desenha, são a nosso ver interessantes para pensar os interlocutores em destaque. Nessa perspectiva, as mulheres e homens de caráter destrutivo, ao contrário das mulheres e homens estojo, encontram-se sempre em trânsito ou no caminho, ou melhor, na encruzilhada:

O caráter destrutivo não vê nada de duradouro. Mas por isso mesmo vê caminhos por toda a parte. Onde outros encontram muros e montanhas, lá, também, ele vê um caminho. [...]. Como vê caminhos por toda a parte, está sempre na encruzilhada. Nenhum momento pode saber o que o próximo o trará (Benjamin, 1979 [1931], p. 302).

Os modos de existência perpassados por tal caráter destrutivo teriam, numa apropriação do texto de Benjamin, tanto uma "desconfiança insuperável na marcha das coisas, como a disposição para, a cada momento, tomar consciência de que as coisas podem correr mal”. Assim, "possuiriam um saber ou uma percepção de que os muros e as montanhas [eu incluiria as obstruções] podem se converter em caminhos" 21.

E é insistindo nesta visada, de positivarmos a precariedade, e de pensarmos as imagens que se desdobram daí, ou seja, de pensarmos a faceta destruição em conexão à precariedade, e da destruição nesta pista explorada por Benjamin, do mesmo modo é ressoar um horizonte de indeterminação. De forma a assinalar nesta articulação precariedade/destruição/indeterminação os sentidos de fuga/circulação/deslocamento. A ampliação, portanto, dos caminhos possíveis ou das veredas e atalhos potenciais a partir

19 Sobre o papel de Lídia e do neopentecostalismo na "transição" da ocupação, ver Birman, 2015.

20 "O carácter destrutivo é o inimigo do homem-estojo. O homem-estojo busca o seu conforto, e a sua caixa é a quintessência dele. O interior da caixa é o rasto revestido a veludo que ele deixou no mundo. O carácter destrutivo apaga até os vestígios da destruição” (Benjamin, 1979 [1931] p. 302).

21 Antonio Negri numa apropriação do texto em questão renomeia esses homens de caráter destrutivo de "os novos bárbaros". Diz ele: “Aqueles que são contra, enquanto escapam das coações locais e particulares da condição humana, precisam também tentar continuamente construir um novo corpo e uma nova vida. Esta é uma transição necessariamente violenta e bárbara, mas, como diz Walter Benjamin, é uma barbárie positiva: 'Barbáries? Exatamente. Afirmamos isto para introduzir uma noção nova e positiva de barbárie. O que a pobreza da experiência obriga o bárbaro a fazer? Começar de novo, começar de novo"” (Negri, 2001, p. 234-235). 
da apropriação da população aqui referida. O pequeno fragmento que segue vai nessa direção. Afinal, a disputa que se colocava de maneira premente pode ser sintetizada nos seguintes termos: como conseguir não protelar mais o desmanche de uma ocupação que, por conta das inúmeras pressões que passava, precisava acabar? E era este, afinal, o momento, mesmo que tenso, ou infernal, em que as oportunidades poderiam surgir. E era preciso não perdê-las ${ }^{22}$.

Foi dessa maneira que a instalação do caos numa dessas ocupações da zona portuária propiciou que ela saísse do "limbo", da indeterminação, da situação de uma espera sem fim (quanto a uma resposta por parte dos agentes governamentais), da exasperação e exaustão subsequentes ${ }^{23}$. Possibilitando que alternativas despontassem efetivamente para os moradores. Nesse sentido, a destruição corporificada pelo assassinato de uma pessoa da ocupação por vizinhos, significou mesmo, se podemos usar uma imagem banal: a gota que faltava para entornar o caldo.

Os poucos moradores que ainda restavam indecisos sobre o acordo com a prefeitura, os poucos militantes que ainda intercediam pela manutenção da ocupação, a Defensoria do Estado que acompanhava o caso, mas que também passava por um processo de desmantelamento de seu Núcleo de Habitação, acabaram por sucumbir. O Ministério das Cidades fez-se então presente de maneira mais direta, na tentativa de garantir a realização dos termos do acordo disponibilizado pela prefeitura ${ }^{24}$.

\section{Epílogo: Escritas da violência e implicações para a etnografia $\left(3^{\circ}\right.$ tempo - cena 4$)$}

Retorno a campo após cerca de dois anos afastada (realizei umas poucas incursões no período em que escrevia a tese). Éuma amiga e pesquisadora - Camila Pierobon - que me reintroduz na última das cinco ocupações que resta. No ano passado seus moradores tiveram os nomes publicados no Diário Oficial, o que significava a garantia para habitar o prédio por 99 anos. Um mês depois desta conquista, a ocupação foi invadida por garotos do tráfico fugidos de um morro próximo que estava recebendo uma UPP. Aos poucos o tal adensamento de ar (Borges, 2010, p. 23) rouba a cena. Os garotos do tráfico e a grande movimentação de uma turba de usuários de drogas na calçada em frente ao edifício, a

22 Sobre processo semelhante, mas passado na capital paulista, ver a tese de Miagusko (2008).

23 Essas observações se filiam tanto a pesquisa de Alexandre Magalhães (2014) sobre remoções na cidade do Rio de Janeiro no contexto dos mega eventos, mencionando os processos de adoecimentodesencadeados por tais ações, quanto às considerações de Adriana Vianna (2014b, 2014a) sobre a espera entre familiares que tiveram seus filhos assassinados pela polícia, e a ideia de terror nesse cotidiano desenvolvida por Anelise Guterres (2016).

24 As alternativas do acordo eram: uma casa em Cosmos, bairro situado a $60 \mathrm{~km}$ do centro, uma indenização de $\mathrm{R} \$ 20$ mil ou o pagamento pela prefeitura de um aluguel social no valor de $\mathrm{R} \$ 400$ reais, na época, por seis meses, com direito a renovação por igual período, caso os imóveis prometidos no Centro não saíssem, e foi isso o que aconteceu e ainda permanece. 
cumplicidade da PM, que vira e mexe dispunha a viatura da corporação na entrada, também as notícias sobre punições, castigos e mortes confirmavam que a "conquista" ou a garantia à habitação, numa região que se transformava intensamente, não significaria o fim da estória.

Voltávamos - Camila e eu - após uma semana de um encontro que se mostrou para nós extenuante. Estórias de enorme violência foram relatadas de forma contínua e por algumas horas. Deise e Janete, principalmente Janete, têm em comum o fato de terem criado os seus filhos praticamente sozinhas. Também de terem chegado à ocupação fugindo da de alguma situação de conflito de cunho familiar. Deise é originária do Rio Grande do Sul e Janete de São Paulo. Deise, segundo suas palavras, depois de morar em São Paulo e depois no Rio de Janeiro, sendo explorada na casa de parente, terminou morando num cortiço no centro da cidade. Janete depois de ter seus filhos envolvidos no tráfico de drogas, dois deles tinham já pago cadeia, acusa o irmão, que mora na zona oeste, por ter sido indiretamente o responsável pela morte do seu outro rebento ${ }^{25}$.

Quando chegamos à casa de Janete, este mesmo irmão estava visitando a mãe, que agora mora com Janete. A mãe já idosa foi diagnosticada com arteriosclerose (não mais em estado inicial). Também foi diagnosticada com câncer de boca. Estas doenças tomam praticamente todo o tempo de Janete, que precisa se desdobrar vinte e quatro horas para cuidar da mãe. A mãe desde o início do ano mudou-se para a sua casa, pois, segundo as duas (Deise e ela), andava muito fraquinha, sem vitaminas, porque o irmão e a mulher do irmão levavam a mãe a base do miojo. Esta, quando apareceu na ocupação, nas palavras acompanhadas de muitos risos de Deise: Parecia, menina, estar de raiban. Essas acusações elas repetiam diante do irmão, ocultando a parte acusatória que cabia a ele e a sua esposa. $\mathrm{O}$ irmão olhava a tv praticamente imóvel e segurava a mão da mãe de modo firme e durante a quase totalidade das três horas que restamos no apartamento de Janete. Ela havia feito dois bolos, todavia o irmão não aceitou comer. $\mathrm{O}$ que chamou ainda mais nossa atenção. Depois que ele foi embora ambas desfiaram um longo rosário de mazelas e tragédias cotidianas concernentes ao próprio.

Dizem que o irmão trabalha com milicianos e que ela, Janete, havia dado queixa dele por maus tratos em relação à mãe. O processo ainda corre porque ela quer que o aluguel que o safado pega, seja dirigido a ela, Janete. Afinal, agora ela tem muitas despesas que apenas a aposentadoria da mãe não consegue dar conta.

Janete faz deliciosas coxinhas de batata doce recheadas de frango. Orgulhase de mandar bem na cozinha. Orgulha-se de ser muito, mas muito braba, quando precisa ser. Mas está muito cansada nesse dia. Diz ter chorado demais com a derrota do Brasil e que comeram muitas pizzas e coxinhas durante e depois da derrota, primeiro pelo nervosismo, depois para esquecer. Enquanto estávamos por lá, coloca a mãe na cama para dormir, e vai ao mercado. A mãe dorme pouco e sempre pede para ir ao banheiro principalmente na madrugada. Ela outro dia caiu, Janete dormia, era já de manhãe estava

25 Sobre a trajetória e o cotidiano de Janete na ocupação ver a tese de Pierobon, 2018. 
muito exausta e não viu que a mãe se levantara. Na quarta édia de feira no supermercado Rede Economia, a fruta émuito mais barata. Pede-nos para ficar com a sua mãe enquanto ela vai rapidamente às compras. Consegue que o garoto do tráfico carregue seu carrinho atéo apartamento. Não estánem á́se vão dizer que ela éassim com o tráfico [fazendo o gesto de aproximar e friccionar os dedos indicadores entre si].

A fixação atual de nossas interlocutoras, como mencionei, é de conseguirem entrar na lista dos apartamentos do Programa Minha Casa, Minha Vida, num bairro vizinho. O conjunto residencial localizado na Av. Frei Caneca, reúne cerca de mil apartamentos, ali antes funcionava um presídio homônimo, esvaziado e implodido para se tornar moradia ${ }^{26}$. O portal da entrada da então cadeia foi preservado e os blocos da frente erguidos bem próximos ao monumental muro característico a muitas casas de custódia. Mas a preocupação de Janete é se o apartamento também terá as indefectíveis baratas - que ela chama de inglesinhas - como há na ocupação [fala apenas desse tipo de baratas, ou seriam de outra espécie?]. Além destas, queixa-se que a região do futuro imóvel é muito diferente da região da Central. Não tem nada próximo, um supermercado, farmácia, ponto de ônibus, nem calçada direito! Já Deise conta que ligaria naquela noite mesmo para a mulher que estaria articulando com um político a inclusão de seus nomes na lista de quem receberá os apartamentos.

$\mathrm{Na}$ despedida marcamos de assistir a final ou a semifinal da Copa de futebol. Mas conseguimos retornar apenas na semana posterior ao último jogo. No início desse novo encontro Janete faz uma declaração que me surpreende. Diz que riram um tanto da gente, de nossas caras, depois das estórias que haviam nos contado na outra semana. E que não sabiam se retornaríamos. Tal declaração em tom confessional, mas também de galhofa, nos pega de surpresa. A espetacularização da violência ganharia traços diferentes neste novo encontro: passam a ter um contorno mais concreto e cotidiano. Era a filha que havia se envolvido com o tráfico e que como era sapatão, mas Janete não conseguia aceitar. Era o filho que morrera após se afogar ou ter sido afogado nas pedras da praia do Arpoador, em Ipanema, um dia depois que ela havia dado queixa do irmão na delegacia. Ela conta-nos que depois disso ficou com tanta raiva do irmão que foi para a rua com os filhos sem ter mesmo um lugar para ir e não quis mais voltar para casa (nesta época ela e o irmão dividiam um mesmo terreno). Foi então que acabou, por outros contatos, chegando à ocupação.

A última cena que apresentei, quando do retorno à ocupação, colocam algumas questões. Como narrar o caráter destrutivo (e situações de violência) de quem precisa se apresentar, constantemente, diante dos agentes da governamentalidade e do estado, como um "pobre coitado" (o que também é uma estratégia dessa mesma governamentalidade e estado para prescreverem a subserviência e cordialidade dos pobres)? Como pensar uma narrativa que evoque as linhas de força disruptivas desses mesmos pobres em relação a 
tal política, portanto, uma certa forma de violência e do caráter destrutivo, sem evocar ou retomar a criminalização dessa população?

A revelação da enorme tensão através do assassinato/linchamento de um morador foi, sob outro ângulo, uma forma de rebater o dispositivo da crueldade (Ulloa apud Epele, 2013 , p. 15) corporificado tanto pela indefinição quanto aos termos do acordo, quanto por pela espera infindável (Vianna, 2015). A ideia de que a ocupação era algo provisório, mas que serviria como moeda de barganha na vida da viração, estava mesmo ameaçada pelas retroescavadeiras, guardas municipais, pelo asfalto remexido e pela presença do tráfico que se instalara na ocupação bem próxima dali.

As palavras lixo, esgoto e merda, e as estórias que as enredavam, quase sempre associadas ao prédio, além de repetidas muitas vezes e por diferentes moradores, indicavam que as dificuldades quanto à convivência eram de uma ordem disruptiva - os excrementos, como sabemos, se constituem num interdito poderoso em várias sociedades, e igualmente, no cotidiano das ocupações.

Como contar uma estória quando ela desconstrói o modo de cordialidade e de subserviência dos pobres com o seu destino? O que significa irromper com as narrativas hegemônicas sobre esses mesmos pobres e rememorar (Benjamin apud Gagnebin, 1999, p. 17) as inumeráveis formas de violência e de silenciamento vigentes em diferentes planos e escalas na sociedade brasileira sem exotizar esse cotidiano? Portanto, tornar a violência e a precariedadefatos extemporâneos e externos à vida social (como são majoritariamente vistos). No caso da penúltima cena, talvez possamos pensar que a morte ocorrida também pode ser considerada uma tentativa para fazer com que o acordo proposto entre prefeitura e moradores se concretizasse e para que a fragilidade (então insuportável) do contexto gerado pela espera sem fim e na indeterminação finalmente se dissipasse.

Ou seja, se não épossível falar das paranoias, ameaças e das várias formas de usurpação e violência que percorrem as cenas narradas, como pensar em um processo de rememoração, de escrita e de esquecimento (para que outros despontem)? Pensar que esses secos que atravessam a escuta (o “engolir a seco”), os engasgos na garganta, os apertos no coração e embrulhos nas vísceras, a necessidade de longos períodos de sono para se recompor das incursões a campo, precisam ser incorporadas à discussão (Vianna, 2014). Não para dizer que nós, antropólogos e pesquisadores, olha como somos tão próximos e humanitários, empáticos ou engajados, mas porque a partir dessa escuta, e na incorporação dessa linguagem insubstituível (Ricouer, 1959, p. 74) e que ele remeteu a imagem de mal 
enquanto contaminação, desvio, insurreição, perambulação, perdiçãose possa elaborar um espaço transicional ou intermediário (Winnicott, 1975) ${ }^{27}$.

Para tanto apresentamos uma breve conversa entre o espaço transicional e intermediário de Winnicott e alguns apontamentos da antropóloga indiana Veena Das situa suas pesquisas nas margens do estado (em minúsculo mesmo) ${ }^{28}$. Lugares nas margens, lugares em que se vive (Winnicott, 1975), intermediários e transicionais, lugares da precariouness, constituídos de múltiplas contribuições e vínculos, perpassados recorrentemente por situações de exceção.

Dessa feita, a pesquisa como porção desse espaço intermediário e de lugar em que se vive produzida na convivência com esses sofrimentos todos, atravessada pelas tentativas de torná-lo novamente habitável, quando já não parece mais ser, sem que a saída seja uma forma de evasão, mas justamente de descida ao ordinário (Das, 2007). Desta maneira, podese tomar o texto como um espaço para o insubstituíveldos interlocutores e do pesquisador, mas também como um espaço onde o silêncio perpetrado às narrativas dos vencidos da história pode ser rememorado e, portanto, torne-se audível. Que seja transmitido e, nessa transmissão, uma outra história do presente ganhe passagem.

Veena Das chama atenção para o fato de que, na ética da responsabilidade política do antropólogo, dois movimentos são importantes: tanto registrar aquilo que o discurso oficial quer apagar - e nisto talvez não estejamos muito longe de uma racionalidade iluminista sobre o valor da "verdade" - quanto o registrar os modos como as pessoas retomam suas vidas cotidianas e rotinas desfeitas:

Não há aqui pretensão alguma de um grandioso projeto de recuperação, mas, simplesmente, a pergunta sobre como podem realizar-se as tarefas cotidianas de sobreviver - ter um teto para cobrir-se, ser capaz de mandar seus filhos para a escola, ser capaz de realizar o trabalho de todos os dias sem o temor constante de ser atacado. Descobri que a reconstrução do eu não se localizava a sombra de um passado fantasmático, mas no contexto de tornar habitável a cotidianidade (Das, 2007, p. 160).

Haveria como que uma dimensão de cura neste "segurar" ou constituir "holding" (Winnicott, 1991) do pesquisador que acompanha seus interlocutores no trabalho

27 Winnicott enfatizou a ideia de espaços limiares, que rompem com a separação dentro e o fora, o eu e o outro (em Winnicott, a mãe [ ${ }^{\star}$ ou quem exerce a maternagem] e o bebê); esses espaços, por sua vez, não seriam efeito da fusão entre os dois "mas um desdobramento das relações fusionais do estado de dependência", nos termos que tratamos anteriormente, da interdependência/condição da precariouness entre os seres. Marcado, portanto, por objetos que ele chamou de transicionais (que ajudam ao processo de separação entre bebê e mãe, vida/perdas): objetos reconhecidos como o paninho com o cheiro da mãe, o ursinho sujo e babado. Esses objetos não se restringem a um momento etário (a primeira infância), Winnicott inclui, e isso é que está nos interessando, a criatividade, a arte, a cultura, religião, etc., como ambientes passíveis, sob certas condições, de propiciar, no decorrer do viver, a invenção de objetos e espaços transicionais (1975).

28 Algumas das reflexões dessa seção encontram-se na comunicação Dimensões políticas do sensível em Veena Das (Fernandes; Ferreira, 2015). 
cotidiano de sobreviver à violência, ao sofrimento e às dores. Esta qualidade da cura como a de uma presença capaz de sustentar uma situação no tempo, "reunindo" diferentes fragmentos das experiências. Nesta perspectiva, uma qualidade de presença e atenção compreendida“como um ficar aí [...]" (Oury apud Ferreira, 2015, p.207), um regime cognitivo baseado em registros da ordem do pré-pático: sensações e percepções que não estão ainda formalizados, "e é nesse plano que podemos ter um 'contato'[...]” (Oury, s/d).

Uma textura das relações, conforme o vocabulário usado por Das, que não é algo transcendental, mas parte do cultivo de uma sensibilidade que se faz na descida à vida ordinária. No qual o hábito pode ser o local do cultivo e não apenas da repetição mecânica. É neste sentido que para a antropóloga de Affliction há um trabalho do tempo que é próprio do antropólogo que seria este "deixar-se marcar pelo conhecimento do outro" (Das, 2007 , p. 17). E que sejamos não apenas pesquisadores ávidos por informações sobre o que nos levou a campo, em busca de um sentido definitivo, ou preenchendo as lacunas e significando as estranhezas e incômodos, mas segurando o que isso tudo é capaz de reverberar em nós, na pesquisa e nos modos de narrá-la.

\section{Referências}

AGAMBEN, Giorgio. Homo Sacer: o poder soberano e a vida nua I. Trad. Henrique Burigo. Belo Horizonte: UFMG, 2004.

AGIER, Michel. Le camp comme limite et comme espace politique in Kobelinksky, Carolina. Et Makaremi, Chowra. Enfermés dehors. Enquêtes sur le confinement dês étrangers. Broissieux/ Bellecombe-en-Beuges: Ed. du Croquant, 2009.

ALVES, Eliane;TELLES,Vera.Territórios em disputa: a produção do espaço em ato. In: TELLES,Vera;CABANES, Robert (org.). Nas tramas da cidade. Trajetórias urbanas e seus territórios. São Paulo: Humanitas, 2006.

BIEHL, João; PETRYNA, Adriana. Tratamentos jurídicos: os mercados terapêuticos e a judicialização do direito à saúde. História, Ciências, Saúde, Manguinhos, Fundação Oswaldo Cruz, Rio de Janeiro, v. 23, n. 1, p. 173-192, 2016. Disponível em: <http://www.redalyc.org/pdf/3861/386144717011.pdf>. Acesso em: 20 abr. 2015.

BIRMAN, Patricia. Cruzadas pela paz: Práticas religiosas e projetos seculares relacionados à questão da violência no Rio de Janeiro. Religião e Sociedade, v. 32, n. 1, p. 209-226, 2012. Disponível em: <http://www.scielo.br/pdf/ rs/v32n1/ a10v32n1.pdf>. Acesso em: 06 dez. 2012.

Ocupações: territórios em disputa, gêneros e a construção de espaços comuns. In: LEITE, Márcia; BIRMAN, Patricia; MACHADO, Carly; CARNEIRO, Sandra. Dispositivos Urbanos e trama dos viventes: ordens e resistências. Rio de Janeiro: Editora FGV, 2015.

BIRMAN, Patricia; FERNANDES, Adriana; PIEROBON, Camila. Um emaranhado de casos: tráfico de drogas, estado e precariedade em moradias populares. Mana, v. 20, n. 3, p.431-460, 2014. Disponível em: <http://www. scielo.br/scielo.php?script=sci_arttext\&pid=S0104-93132014000300431 >. Acesso em: 11 nov. 2015.

BENJAMIN, Walter. [1940]. Sobre o conceito de história. Trad. Jeanne-Marie Gagnebin e Marco Lutz Muller In: Lowy, Michel. Walter Benjamin: aviso de incêndio. Uma leitura das teses "Sobre o conceito de história". São Paulo: Boitempo, 2005.

[1931] The Destructive Character. In: DEMETZ, Peter (ed.). Reflections. Walter Benjamin, essays, aphorisms, autobiographical writings. Transl. Edmund Jephcott. New York: A Harvest/ HBJ Book, 1979

BOR GES, Fabiane. Domínios do demasiado. São Paulo: Hucitec, 2010.

BUTLER, Judith. Introducción: Vida precária, vida digna de duelo. In: Marcos de guerra. Las vidas lloradas. Trad. Bernardo Moreno Carrillo. Madrid: Paidós, 2010. 
BUTLER, Judith. Comunicação oral. Simpósio XV Simposio de la Asociación Internacional de Filósofas. Universidad de Alcalá, 2014. Disponível em <https://www.youtube.com/watch?v=hEjQHv0R6rQ>.Acesso em 10 out. 2014.

CAIAFA, Janice. Três palavras. In: Trópico (online) s/d. Disponível em: <http://p.php.uol.com.br/tropico/html/ textos/2621,1.shl>. Acesso em: 13 maio 2014.

DAS, Veena. Affliction. Health, Disease, Poverty. New York: Fordham University Press, 2015.

Entre Palavras e vidas. Um pensamento de encontro com margens, violência e sofrimento (entrevista). In: MICHE, M.; BIRMAN, P.;WERNECK, A.; FELTRAN, G.; MALVASI, P. Dilemas, v.5, n. 2, p. 335-356, 2012.

Fronteiras, violência e o trabalho do tempo: alguns temas wittgensteinianos. Revista Brasileira de Ciências Sociais, v. 14, n. 40, p. 31-42, 1999.

.The Event and the Everyday. Life and words. Violence and the descent into the ordinary. California: University of California Press, Berkley and Los Angeles, 2007.

DE LUCCA, Daniel. Nem dentro nem fora do albergue: transformações e usos de um dispositivo da assistência. In: CUNHA, Neiva; FELTRAN, Gabriel. Sobre periferias: Novos conflitos no Brasil contemporâneo. Rio de Janeiro: Editora Lamparina, 2013.

DELEUZE, Gilles. Um manifesto a menos (sobre a obra de Carmelo Bene). In: Sobre teatro. Trad. Fátima Saad. Rio de Janeiro: Jorge Zahar Ed., 2010.

DELEUZE, Gilles; PARNET, Claire. Psicanálise morta análise. In: Diálogos. Trad. Eloísa Araújo Ribeiro. São Paulo: Ed. Escuta, 1998.

DELEUZE, Gilles; GUATTARI, Felix. Mil Platôs. Trad. Suely Rolnik. São Paulo: Ed. 34, 1997. (v. 4).

EPELE, Maria. Introducción. In: EPELE, Maria (org.). Padecer, cuidar y tratar. Estudios sócioantropológicos sobre consumo problemático de drogas. Buenos Aires: Paidós, 2013.

Sujetar por la herida. Una etnografía sobre drogas, pobreza y salud. Buenos Aires: Paidós, 2010.

FERNANDES, Adriana. Escuta ocupação: arte do contornamento, viração e precariedade no Rio de Janeiro.2013. Tese - Programa de Pós-Graduação em Ciências Sociais, Universidade Estadual do Rio de Janeiro, Rio de Janeiro, 2013.

FERNANDES, Adriana; FERREIRA, Mariana. Dimensões políticas do sensível em Veena Das (comunicação).V REAABANNE (Reunião de Antropologia Norte e Nordeste), Maceió, 2015.

FERREIRA, Mariana. Ensaios sobre a compaixão: sofrimento, engajamento e cuidado nas margens da cidade. 2015. Tese Programa de Psicologia de Aprendizagem e do Desenvolvimento/IP, Universidade de São Paulo, São Paulo, 2015.

Direitos humanos e psicologia: sobre cascas, feridas e lampejos em Experiências em psicologia e direitos humanos/Conselho Regional de Psicologia do Rio de Janeiro. (1º lugar, Prêmio Beatriz Sá Leitão, 2016). Caderno Anual, n.2, ano 2017. Disponível em: <http://www.crprj.org.br/site/wp-content/uploads/2017/08/caderno_ IIbia.pdf>. Acesso em: 03 maio 2016.

FOUCAULT, Michel. História da Sexualidade I. A vontade de Saber. Trad. Thereza Albuquerque e J. Guillon Albuquerque. Rio de Janeiro: Graal, 1985.

GAGNEBIN, Jeanne-Marie. Da dignidade ontológica da literatura. In: NASCIMENTO, Fernando; SALLES, Walter. Paul Ricouer. Ética, identidade e reconhecimento. Rio de Janeiro: PUC-RJ/Ed. Loyola, 2013.

História e Narração em Walter Benjamin. São Paulo: Editora Perspectiva, 1999.

Lembrar, escrever, esquecer. São Paulo: Ed. 34, 2006.

. Uma filosofia do cogito ferido: Paul Ricouer. Estudos Avançados, v. 11,n. 30,p. 261-272, 1997.

FROMM, Deborah. Percursos e refúgios urbanos: Notas sobre a circulação de usuários de crack pela trama institucional da Cracolândia de São Paulo. In:TELLES, Vera (org.). Em torno da cracolândia paulista. Ponto Urbe, v. 21, 2017. Disponível em <https://journals.openedition.org/pontourbe/3602>. Acesso em 05 dez. 2017. 
GUTERRES, Anelise. O rumor e o terror na construção de territórios de vulnerabilidade na zona portuária do Rio de Janeiro. Mana [online], v.22, n.1,p.179-209, 2016. Disponível em: <http://www.scielo.br/scielo. php?script=sci_arttext\&pid=S0104-93132016000100179>. Acesso em: 06 jun. 2017.

MAGALHÃES, Alexandre. Transformações no "problema favela" e a reatualização da "remoção" no Rio de Janeiro. 2013. Tese - Instituto de Estudos Sociais e Políticos, Universidade do Estado do Rio de Janeiro, Rio de Janeiro, 2013.

MAGALHÃES,Tais. Campos de disputa e gestão do espaço urbano: a Operação Sufoco na “cracolândia" paulistana. In: TELLES, Vera (org.). Em torno da cracolândia paulista. Ponto Urbe, v. 21, 2017. Disponível em: <https:// journals.openedition.org/pontourbe/3602>. Acesso em: 05 dez. 2017.

MALLART, Fábio; RUI, Taniele. Cadeia ping-pong: entre o dentro e o fora das muralhas. In:TELLES,Vera (org.). Em torno da cracolândia paulista. Ponto Urbe, v. 21, 2017. Disponível em: <https://journals.openedition.org/ pontourbe/3602>. Acesso em: $05 \mathrm{dez} .2017$.

MARTINEZ, Mariana. A produção e a gestão da população de rua: A trajetória de Luciene. Dilemas, v. 7, n. 4, 2014. Disponível em: <https://revistas.ufrj.br/index.php/dilemas/article/view/7260>. Acesso em: 06 dez. 2016.

MIAGUSKO, Edson. Movimentos de moradia e sem-teto em São Paulo. Experiências no contexto do desmanche. 2008. Tese - Programa de Pós-Graduação em Sociologia, Universidade de São Paulo, São Paulo, 2008.

NASSER, Marina. Cracolândia como campo de gravitação:A gestão da circulação de pessoas com acesso precário à moradia In: TELLES, Vera (org.). Em torno da cracolândia paulista. Ponto Urbe, v. 21, 2017. Disponível em: <https://journals.openedition.org/pontourbe/3602>.Acesso em: 06 dez. 2017.

NEGRI, Antonio. Império. Trad. Berilo Vargas. Rio de Janeiro: Record, 2001.

OURY,Jean. (s/d). Le pré-pathique e le tailleur de pierre. Chimeres. Disponível em: <http://www.revue-chimeres. fr/drupal_chimeres/files/40chi04.pdf>.Acesso em: 04 jul. 2017.

PIEROBON, Camila. Tempos que duram, lutas que não acabam: o cotidiano de Leonor e sua ética de combate. 2018. Tese Programa de Pó-Graduação em Ciências Sociais, Universidade do Estado do Rio de Janeiro, Rio de Janeiro, 2018.

RICOUER, Paul. Le symbole donne à penser. Esprit, n. 27, p. 7-8, 1959.

RUI, Taniele. Fronteiras e usos do crack. In: CUNHA, Neiva; FELTRAN, Gabriel. Sobre periferias: novos conflitos no Brasil contemporâneo. Rio de Janeiro: Editora Lamparina, 2013.

RUI, Taniele; MARTINEZ, Mariana; FELTRAN, Gabriel. Novas Faces da Vida nas ruas. São Carlos, SP: EdufsCar, 2016.

Em torno da cracolândia paulista (apresentação de Dossiê). Ponto Urbe, v. 21, 2017. Disponível em: <https://journals.openedition.org/pontourbe/3602>.Acesso em: 05 dez. 2017.

TELLES, Vera da Silva. A cidade nas fronteiras do legal e ilegal. Belo Horizonte: Argvmentvm, 2010.

VIANNA, Adriana. Dos corpos que não estão ali, mas tentam estar: sobre se fazer ver/ouvir no espaço da "Justiça (comunicação oral). Seminário (in)scrituras: sobre marcas e mapas corporais-espaciais. Universidade Federal do Rio de Janeiro, Museu Nacional, 2014a.

Violência, estado e gênero: considerações sobre corpos e corpus entrecruzados. In: LIMA, Antonio Carlos de Souza;GARCIA-ACOSTA,Virginia (org.). Margens da violência. Subsídios ao estudo do problema da violência nos contextos mexicanos e brasileiros. Brasília: ABA, 2014b.

. Tempos, dores e corpos: considerações sobre a "espera" entre familiares de vítimas de violência policial no Rio de Janeiro. In: LEITE, Márcia;BIRMAN, Patricia;MACHADO, Carly;CARNEIRO, Sandra. Dispositivos Urbanos e trama dos viventes: ordens e resistências. Rio de Janeiro: Editora FGV, 2015.

WINNICOTT, W. O brincar e a realidade. Trad. José Octávio de Aguiar Abreu e Vanede Nobre. Rio de Janeiro: Imago, 1975.

Holding e interpretação. Trad. Sonia Maria de Barros. São Paulo: Martins Fontes, 1991. 


\title{
Images of precariousness, governance of the poor and ethnographic implications
}

\begin{abstract}
Through field work on housing occupations located in the center of Rio de Janeiro, I propose to think how precariousness - images, senses, effects - is important in this experience. The political context with the election of Lula da Silva as president favored the occupation movement. A few years after there was a retraction: the announcement of a gentrification project of the area, Porto Maravilha, which has gradually become a policy of expulsion of the poor from the region. For the residents I observed this has resulted in a worsening of the material conditions and the experienced relations in occupied buildings. I approach how they sought to circumvent these gentrification policies. On the last section, the discussion falls on some of the ethical implications raised when the field of research is characterized by precarious situations.
\end{abstract}

Keywords: Popular housing, poor, precarity, ethnography.

\section{Imágenes de la precariedad, gobierno de los pobres e implicaciones etnográficas}

\section{Resumen}

A través del trabajo de campo en las ocupaciones de viviendas en régimen de autogestión, situados en el centro antiguo de la ciudad de Río de Janeiro, propongo pensar como la precariedad - sus imágenes, sentidos, efectos - fueron y son importantes en esta experiencia. El contexto político con la elección de Lula da Silva como presidente era algo alimenta positivamente este escenario. Unos años más tarde, sin embargo, hubo un movimiento contrario: el anuncio de un área del proyecto gentrificación ("Porto Maravilha") se convirtió en la expulsión gradual de políticas y/o amenazas de expulsión, de origen más pobre que vivía en ciertas áreas. Para los residentes de las ocupaciones que le siguió dio lugar a un empeoramiento de las condiciones materiales y de interrelación de los edificios. Abordo aquí como ellos buscaron eludir esas políticas de gentrificación. En la última sección, la discusión recae sobre algunas de las implicaciones éticometodológicas suscitadas cuando el campo de la investigación se caracteriza por situaciones de precariedad.

Palabras-clave: Ocupaciones de vivienda, pobres, precariedad,etnografia. 